\title{
Green Mining - A Holistic Concept for Sustainable and Acceptable Mineral Production
}

\author{
PEKKA A. NURMI \\ Geological Survey of Finland, Espoo, Finland \\ pekka.nurmi@gtk.fi
}

\begin{abstract}
Mining has become increasingly difficult for societal and environmental reasons all over the world. There is an increasing competition with other land uses, and water and energy are scarce in many important mining regions. People are not ready to radically reduce the use of mineral-based products, but increasingly oppose mining. The industry faces major challenges to improve its performance and image.

The Green Mining concept (GM) was developed as a major tool to make Finland the forerunner in sustainable mining. It promotes material, water, and energy efficiency to reduce the environmental footprint of mineral-based product life cycles. GM allows the recovery of all useful minerals and minimises mining waste. GM aims to ensure the availability of mineral resources for future generations, which requires long-term investment in mineral exploration supported by geoscientific mapping, mineral systems research and the development of exploration techniques. An important goal of GM is to minimise adverse environmental and social impacts in all stages of the operations, and to maximise local benefits. GM helps to organise the operations in such a way that they are safe and meaningful to employees, and harmless for local residents and the environment. After mine closure, GM helps to restore the mining areas to make them safe and preferably to allow other types of land use. The broadbased participation of local residents and other stakeholders is crucial throughout the mining life cycle, from early exploration to mine closure.

Societies, governments, and investors should not tolerate unsustainable mining companies in the future. The mining industry has to solve increasing social, ecological and technical problems of the future by applying holistic concepts, such as the Green Mining concept, if they hope to earn the social license to operate.
\end{abstract}

\section{INTRODUCTION}

$\mathrm{G}$ lobalization, the growth of the middle class in most developing economies, and the rapid development of technologies have created growing interest in mineral resources. According to the United Nations, the world's population will rise to 9 billion and 3 billion new people will move to cities by 2050 (United Nations, 2012). The total consumption of metals will definitely be higher in the future due to the increasing global population and numbers of middle-class people, although consumption per capita will be lower because of improved resource efficiency, recycling, better product design, and substitution of traditional metals by new materials (World Economic Forum, 2015). Economic mineral deposits are very special rock types that are rare and typically small occurrences within Earth's crust. The formation of economic mineral deposits is governed by complex processes, and their occurrences are typically controlled by large-scale structures and characteristic geological formations. The mining of minerals and their use in downstream industries or as final products largely take place in different continents and countries. For example, EU member countries consume $20-30 \%$ of the metals produced globally, but metal mine production within the EU accounts only for a few per cent of global production and many metals are not produced at all (Brown et al., 2016). On the other hand, minerals-based industries are of crucial importance for the EU. The combined annual economic effect of the construction, chemical, automobile, aeroplane, machinery and equipment-manufacturing industries is about 1,300 billion euros, and they provide employment for 30 million people (Tiess, 2010). 
Resource efficiency will reduce dependency on primary minerals, but EU industries will remain vulnerable to disruptions in the metal supply and to market volatility for many decades to come. Thus, one of the challenges for the sustainability of the raw material supply chain in Europe is to enhance domestic production of not only the critical metals but also the traditional ferrous and base metals (Nurmi and Mólnar, 2014). The EU has reacted to the situation by launching the raw materials initiative (European Commission, 2008) and by listing the critical minerals (European Commission, 2014), which are particularly important for the industries and have potentially uncertain availability due to their concentrated production in certain countries, such as rare earth elements in China or cobalt in the Democratic Republic of Congo (Nansai et al., 2014). Most people are actively seeking a better standard of living and a modern life style, and they are not therefore ready to radically reduce their consumption. Despite this, many are increasingly opposed to mining activities in or near their communities, or within environmentally vulnerable areas, such as the Arctic region. Many people seem to have little or no understanding of the role of minerals in their urban-style everyday life, or that mining is the only way to obtain the minerals necessary for making all the infrastructure and wanted goods. Anti-mining groups can be globally organised or locally active. They are typically driven by ideological enthusiasm. They are well organized and have good visibility, partly due to their good social media skills.

People also increasingly oppose mineral exploration, and it is very difficult to make the difference understood between exploration projects, which can operate over large areas, cause very low impacts and which seldom lead to mining operations, and mining itself, which may cause high impacts but in small areas.

The mining industry has a poor image. It is based mainly on past mistakes and neglecting the voice of local communities, or on various more recent conflicts and severe accidents that have gained global visibility. Although most mines operate in a sustainable way and the industry has improved, in general, the failures can be actively used as examples to hinder new mine development in any area. The mining industry as a worldwide entity has also failed to eliminate ongoing problems with pollution and human-rights abuses (e.g., conflict minerals, working conditions in artisanal mines, etc.), or to mitigate the problems of past mining activities that remain with us today. Public scepticism of mining is rooted in this reality.

\section{CHALLENGES FOR THE MINING INDUSTRY}

The mining industry is facing multiple problems (PricewaterhouseCoopers International, 2013), which makes the long-term planning of sustainable mineral production and prediction of the availability of various commodities a difficult task for individual companies, nations or globally (Ali et al., 2017). Geology defines the occurrence of ore deposits. Most traditional mining regions have been explored and mined for decades, and the remaining ore bodies are located deeper in the earth's crust, making exploration expensive and discoveries much more difficult. Geologists have to go to new areas, which are located in remote regions with a less developed infrastructure and more difficult working conditions. New deposits, moreover, tend to be of lower grade and / or more difficult to process. Decision making in connection with exploration investments is never based solely on the geological potential, but takes into account numerous other issues. Land access and the legal framework are critical factors for the minerals industry. Competition with other land use purposes (such as agriculture, the conservation of natural or historical landscapes, infrastructural building) are causing increasing hurdles for mineral exploration. There is a threat that only limited areas will be available for mineral exploration surveys in the future. Mine development is also becoming increasingly difficult for societal and environmental reasons. There is increasing competition with other interests in society, such as biological diversity, tourism, and recreation. Tightening laws and regulations will make future mining more difficult in many countries. In some regions, it is impossible to find enough energy and water, and it may be difficult to find feasible means of transport. 
The mining industry seems to have lost much of its attractiveness among younger generation. It has an image of an old fashioned, polluting and dangerous business. For example, many universities ended their mining-related curricula in the 1990s, and now it is difficult to rebuild them due to the lack of competent teaching personnel and reduced appeal among young students.

The mining industry needs long-term planning, requires adequate capital and includes high risks. Successful mineral exploration is the basis for sustainable mining. Exploration needs high-risk investment in projects that only seldom lead to economic discoveries. The time needed to bring a new deposit into production from the start of the exploration project can easily be 10 to 15 years. Commodity prices are highly volatile, and during the operation time of a major mine there are many ups and downs. One of the difficulties is the timing of the initial investment to be able to turn the cash flow positive within the first few years. Few companies are willing to invest during a low commodity price cycle. Mine building typically takes several years, and investment during the peak may mean that at the start of production the good times could be over for multiple years. The use of many critical minerals changes with time and technological development, which makes long-term investments risky in the hi-tech commodities sector. Investors also feel a threat from the strengthening demands of resource nationalism.

Mining is a global business, and in many countries foreign companies are involved in exploring and developing mines. People are asking about the benefits to their country and local communities. Operating rules and conditions in an area might change in unpredictable ways because of a new legal framework, taxation regime or, in the worst case, due to a national takeover.

\section{THE GREEN MINING CONCEPT}

Finland's Green Mining concept was developed in 2011 as a major tool to make Finland the forerunner in sustainable mining (Nurmi and Wiklund, 2012). This concept is based on five pillars (Fig. 1).

\section{Promoting materials and energy efficiency}

Green Mining promotes materials and energy efficiency, which reduces the environmental footprint of mineral-based product life cycles. Methods that save energy and materials in mining and the enrichment of minerals have to be developed.

The purpose of these new solutions is to allow the recovery of all useful minerals and byproducts, and to minimise the amount of waste. Solutions for reducing water and energy consumption are being developed. In order to achieve a result that is best for the entire mining operation, there needs to be a reliable way of measuring the material and energy efficiency and the environmental footprint during the life cycle.

The lifespan of many mineral-based products is long and commodities are recyclable in most applications. Therefore, once produced, metals and minerals remain available for future generations, and sustainable societies will create effective mechanisms for recycling and reducing the growing need for primary resources.

\section{Ensuring the availability of mineral resources for the future}

Mineral raw materials are unevenly distributed across the Earth and concentrated in small volumes of the crust through distinct geological processes. Mineral deposits as such are nonrenewable and ore reserves at existing metal mines are finite. Continuously increasing demand for mineral resources will exhaust most existing mines within the next few decades, although many mines will have a much longer lifetime than can be estimated according to present ore reserves.

Green Mining aims to ensure the availability of

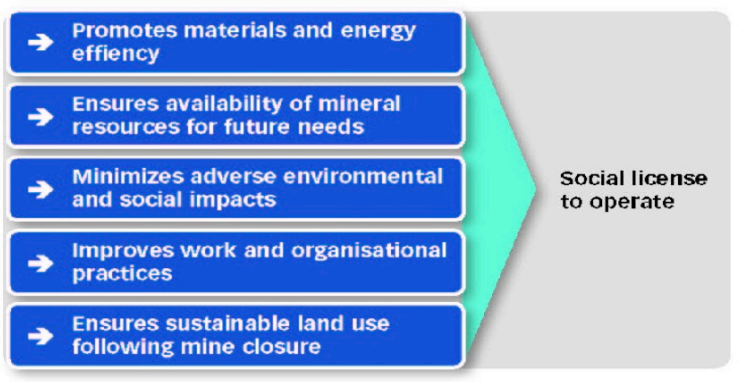

Figure 1: The Green Mining concept of Finland. 
mineral resources for the future.

Sustainable development requires that our current use of mineral resources does not endanger the ability of future generations to satisfy their needs. In order to ensure the availability of mineral resources for future needs and to fulfil the so-called "mineral debt", we must continue geoscientific mapping and research, and invest in mineral exploration.

The development of exploration, mining and processing techniques is also needed to be able to discover and use new types of deposits.

Exploration surveys for economic minerals should be performed in such a way that their impacts on the environment and surrounding societies remain minimal.

Societal judgment of contrasting land use purposes and a decision on possible mine development cannot be made in a balanced way without detailed knowledge of the reserves in an area or the feasibility of the mineral deposit.

\section{Minimising adverse environmental and social} impacts

Mining operations always impact on the natural environment, economy and social structure of the region. The goal of Green Mining is to minimise the adverse environmental and social impacts in all stages of the operations.

At the same time, the operations strive to maximise social and local benefits.

Minimising the adverse environmental impacts requires the development of better control and measurement methods that take into consideration the special characteristics of mining operations and the local natural conditions.

Maximising the societal, economic and cultural impacts in a sustainable way requires research, communication and methods that allow broadbased community participation.

Participation is especially important at the regional level, because this allows the corporate social responsibility of the mines to be executed in the best possible way.

An important question concerns the sharing of benefits.

Green Mining aims at the fair sharing of benefits. All stakeholders must benefit from mining, and the industry should create a long-term positive impact on regional development.

Improving work and organisational practises
Mining takes place in harsh conditions, often underground, employing heavy machinery and a variety of chemicals and explosives, which always involves potential safety hazards. Work must be organised in such a way that it is safe and meaningful to employees. This can be achieved by automating processes and making them more efficient, as well as by developing new practices and working methods in cooperation with the entire staff. The need for strict health and safety standards and practices is self-evident, as well as education aiming at a good working culture. Occupational safety aiming at zero accidents is an important starting point in all development. Operations must also be safe for local residents and the environment. Increasing automation and the development of technologies helps to reduce the need for a workforce and will improve safety. The mining organisation will become lighter and most operations will be executed in mines and enrichment plants using remote control.

\section{Ensuring sustainable land use following mine closure}

The operating time for individual mines can be over a hundred years, but is always limited. After this, the mining areas must be restored to make them safe and allow other kinds of land use. Planning of the controlled ending of mining operations and the proper measures for achieving this is started well before the commencement of mining operations, and is developed throughout the project's life cycle with the broad-based participation of local residents and other stakeholders.

Closure of a mine also requires functional and tested technical and scientific methods, so that the quarries, waste areas and other infrastructure can be restored in a way that allows further sustainable use of the area according to the plans. The costs of reclamation must be factored into the commodity cost, and funds to accomplish reclamation must be set aside.

\section{Finland's Green Mining programme}

Many companies, nations and international organizations plan, finance and systematically develop technologies and practices for resource efficiency. A good example is the Circular 
Economy Initiative by the EU, and the various project calls in its Horizon 2020 programme. In Finland, following the suggestions of Finland's mineral strategy (Anonymous, 2010), the Finnish Fund for Innovation launched the Green Mining R\&D\&I Program (GMP) in 2011. The GMP was a comprehensive approach to Green Mining. It targeted technologies and service innovations and new businesses that bring together value networks of small and medium-sized companies, research institutes and universities in Finland and globally. Following the slogan "Finland, a leader in Green Mining 2020," this five-year GMP turned out to be a trigger for development in all Green Mining areas. GMP employed international networking and drew on the best international practices.

GMP (operated in 2011-2016) had a budget of $€ 115$ million and included 98 projects performed by 175 partners from large and SME sector industry and service companies, research institutes and universities in Finland and globally (Tekes, 2016). The projects aimed at creating improvements in all areas of the Green Mining concept. The results and new innovations include resource efficient processing, water issues, waste problems, exploration techniques, social issues, improved measurement techniques, and new service and organizational practices (Tekes, 2016). The full impact of the results will be seen in the future.

\section{DISCUSSION}

Mining of primary minerals will grow for at least several decades to come. A powerful circular economy is inevitable, but it cannot alone solve the growing mineral needs of billions of new urban people, and new technologies. The economy, society, energy, infrastructure, transportation and materials will look very different in the latter half of the 21st century compared to the present. Metal consumption per capita will decrease, but global consumption will increase due to the growing population and numbers of middle-class people (World Economic Forum, 2015). Therefore, the mining and metals industry will have a significant role to play in future societies (Ali et al., 2017). Future manufacturing will pay special attention to product design, which will allow effective recycling of all commodities. Technological development will allow the substitution of some critical metals by other compounds. On the other hand, rapid technological development and new innovations will require new raw materials for the next generation low-carbon, hitech society, which makes it very difficult to forecast the future critical elements (Vidal et al., 2013). Therefore, it is impossible to estimate in detail the global needs for various mineral raw materials of the next generations.

The availability of commodities is controlled not only by geological accessibility, but increasingly by the availability of water and energy, and by social constraints, politics, legislation and environmental regulations. Gamechanging technological innovations for exploration and extraction are needed. Many of the future intelligent mines will be based on safe robotics, digital technologies and safe automatic processes; they will use less energy and water, and will employ the concepts of zero waste and zero accidents.

Thus far, the majority of mining operations have used resources at or near the surface. A major challenge for future mineral production is the increasing difficulty of ore discovery. Deep-seated deposits remain largely unknown and it is likely that many of the remaining undiscovered deposits are located deep in the crust, under thick overburden or water, or in remote or sensitive places, such as the Arctic regions.

Better geological knowledge, including mapping, geophysics and mineral systems understanding, will have crucial importance for sustainable raw materials management. Long-term investment in geoscientific mapping and research is the basis for mineral exploration, and is essential to ensure a sufficient supply of economic minerals for the future. Some studies demonstrate that considerable resources of economic minerals remain undiscovered (Herrington, 2013; Singer, 2017).

Future mining will increasingly involve deep underground operations (e.g., Sahu et al., 2015), but it will be difficult to find and economically extract all the commodities needed by future communities from deep in the crust, and large, low-grade, open-pit deposits cannot 
be avoided. In the far future, the global resources base may be supplemented by resources from new frontiers, such as the oceans, seafloor and/or extra-terrestrial sources.

Companies need to improve stakeholder relationships and partnerships with a commitment to delivering shared value to industry, governments and communities. Challenges in converting natural resource wealth into sustainable economic growth and the long-term development of mining regions have to be solved. In various countries, voices of resource nationalism are strengthening, demanding special mining taxes or domestic, often public involvement in the mining business. People also want limits for foreign ownership, and mandated beneficiation and export levies.

The mining industry has largely failed to convince people of its necessity for future development. Societies, governments and investors will not tolerate unsustainable mining companies in the future. The mining industry has to solve the increasing social, ecological and technical problems by applying holistic concepts, such as the Green Mining concept, to earn the social license to operate.

\section{ACKNOWLEDGMENTS}

I thank my numerous colleagues at the Geological Survey of Finland, other institutes, universities and companies for successful co-operation in developing the Green Mining concept, and implementing it in numerous projects. I also thank Vince Cronin and Giuseppe Di Capua for their constructive comments and helpful suggestions which helped me to improve the manuscript.

\section{REFERENCES}

Ali S.H., Giurco D., Arndt N., Nickless E., Brown G., Demetriades A., Durrheim R., Enriquez M.A., Kinnaird J., Littleboy A., Meinert L.D., Oberhänsli R., Salem J., Schodde R., Schneider G., Vidal O. and Yakovleva N. (2017). Mineral supply for sustainable development requires resource governance. Nature 543, 367-372.

Anonymous (2010). Finland's Minerals Strategy. Geol. Surv. Finland. Available online at http:/ / projects.gtk.fi/ export/

sites / projects / mineraalistrategia/documen ts / FinlandsMineralsStrategy_2.pdf, last accessed 21 February 2017.
Brown T.J., Hobbs S.F., Idoine N.E., Mills A.J., Wrighton C.E. and Raycraft E.R. (2016). European Mineral Statistics 2010-2014. British Geol. Surv., Keyworth, Nottingham, 378 p.

European Commission (2008). The raw materials initiative - meeting our critical needs for growth and jobs in Europe. COM (2008) 699, 14 p. Available online at http://eurlex.europa.eu/LexUriServ/LexUriServ.do? uri=COM:2008:0699:FIN:EN:PDF, last accessed 15 February 2017.

European Commission (2014). Report on critical raw materials for the EU. Available online at http://www.catalysiscluster.eu/ wp / wpcontent / uploads / 2015/05/2014_Cr itical-raw-materials-for-the-EU-2014.pdf. Accessed 14 March 2017, last accessed 15 February 2017.

Herrington R. (2013). Road map to mineral supply. Nature Geoscience 6, 892-894.

Nansai K., Nakajima K., Kagawa S., Kondo Y., Suh S., Shigetomi Y. and Oshita Y. (2014). Global flows of critical metals necessary for low-carbon technologies: The case of neodymium, cobalt, and platinum. Environ. Sci. Technol., 48 (3), pp 1391-1400.

Nurmi P.A. and Wiklund M.L. (2012). Finland is developing Green Mining. Géosciences 2012: 15, 36-41.

Nurmi P.A., Molnár F. (2014). The future of metal minerals mining in the EU. European Geologist 37: 12-19.

PricewaterhouseCoopers International (2013). Mine - A confidence crisis. Review of global trends in the mining industry - 2013, $59 \mathrm{p}$. Available online at http:/ / www.pwc.com/ en_GX/gx/mining/publications/assets / p wc-mine-a-confidence-crisis.pdf, last accessed 14 March 2017.

Sahu H.B., Prakash N. and Jayanthu S. (2015). Underground mining for meeting environmental concerns - A strategic approach for sustainable mining in future. Procedia Earth and Planetary Science 11, 232 - 241.

Singer D.A. (2017). Future copper resources. Ore Geol. Rev. 86, 271-279.

Tekes (2016). Green Mining - Results of the Tekes Programme 2011-2016. Available online at http://finlandinnovation.fi/ greenmining/, last accessed 10 March 2017. 
Tiess, G. (2010). Minerals policy in Europe: Some recent developments. Resources Policy 35, 190-198.

United Nations (2012). World Urbanization Prospects: The 2011 Revision. United Nations publication, ST/ESA/SER.A/322. United Nations, New York, $302 \mathrm{p}$.

Vidal O., Goffé B. and Arndt N. (2013). Metals for a low-carbon society. Nature Geoscience 6, 894-896.

World Economic Forum (2015). Mining and metals in a sustainable world. Available online

http:/ / www3.weforum.org/docs/WEF_M

M_Sustainable_World_2050_report_2015.pd fAccessed 15 March 2017 , last accessed 15 February 2017. 